\title{
Accelerated Pavement Testing at University of Žilina
}

\author{
Ján Mikolaj, L’ubomír Pepucha, Katarína Zgútová, and L’uboš Remek
}

\begin{abstract}
The paper deals with the Accelerated Pavement Testing method. The aim is to describe the nature of this kind of testing, practical foreign experiences and benefits. The main aim is to describe the design of facility which is the subject of a project solved on the Faculty of Civil Engineering of University of Žilina. The result are summarized in final chapter in which the paper describes expected usage of this facility and way how the measured results may be used in practice. Throughout the whole research methods of analysis, synthesis and deduction were applied.
\end{abstract}

Index Terms-APT, pavement, testing.

\section{INTRODUCTION}

The Pavement Management System (PMS) as part of the civil engineering management branch is fairly good theoretically developed area. The current PMS developed in the 90 's enabled road administrators to manage rehabilitation works throughout the road network for more than 15 years. The system as well as the pavement design method is based on calculation of layered elastic half-space which is heavily reliant on correctness of data for used materials and design. The need for testing able to provide such data arise as the practical experience shows that there is difference between calculated serviceability of pavement and actual results under real traffic load.

\section{APT Method as Part of the PaVement Testing THEORY}

The general principle of APT testing is to apply artificially inducted load similar to real life traffic load in a compressed time period, thus providing an expedited means of evaluating factors associated with traffic-pavement interaction. APT is essentially a full-scale laboratory test during which loaded truck wheels are used to traffic sections of full-scale road pavement constructed using conventional techniques.

There are various pavement testing methods at our disposals each with its own shortfalls and benefits. Pavement testing differs apart from general principle mainly in terms of reliability and time/money costs. APT lies between laboratory testing and Long term monitoring (LTPP- Long Term Pavement Performance monitoring). The quantity of

Manuscript received Fabruary 6, 2013; revised May 20, 2013. This contribution is the result of the project implementation: "Independent search of Civil Engineering Construction for Increase in Construction Elements Effectiveness" (ITMS: 26220220112) supported by the Research \& Development Operational Programme funded by the ERDF.

The authors are with the University of Žilina, Faculty of Civil Engineering, Department of Construction Management, Univerzitná 8215/1, 01026 Žilina, Slovakia (e-mail: jan.mikolaj@fstav.uniza.sk, pepucha@fstav.uniza.sk, katarina.zgutova@fstav.uniza.sk, lubos.remek@fstav.uniza.sk). data that is collected for a corresponding cost and time period is illustrated, in simplified form, in Fig. 1.

There is considerable ongoing debate with regard to the relationship between results obtained from APT, LTPP monitoring and laboratory testing. To date, there have been minimal formal comparative experiments anywhere in the world, although numerous ad hoc studies have been carried out in a number of countries.

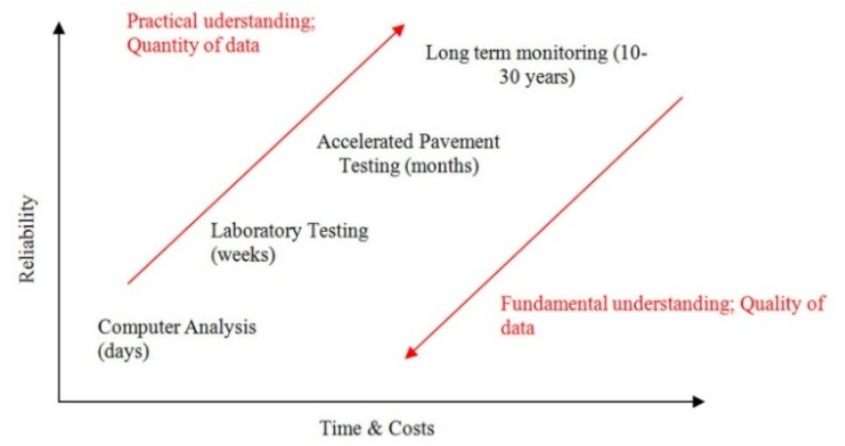

Fig. 1. Pavement testing methods with regards to reliability and costs.

Strategically focused, needs driven pavement research programs have been shown to be most successful when carried out using a combination of laboratory, APT and LTPP data collection studies in conjunction with standard pavement management system monitoring procedures. Each plays an important role and no one component can be used to answer all questions pertaining to the performance of road pavements.

TABLE I: THE ARRANGEMENT OF CHANNELS

\begin{tabular}{|l|l|l|l|l|}
\hline Parameter & Computer & Laboratory & APT & LTPP \\
\hline Materials & Yes & Yes & Yes & Yes \\
\hline Stress regimes & Yes & Yes & Yes & Limited \\
\hline Distress & Yes & Limited & Yes & Yes \\
\hline Geometry/system & Yes & No & Yes & Yes \\
\hline Environment & Yes & Controlled & Controlled & Yes \\
\hline Traffic & Yes & No & No & Yes \\
\hline
\end{tabular}

As we can see various research methods play individual roles in terms of researched parameters, their reliability and cost/time data. These research approaches should be all part of a strategically focused (or holistic) pavement research programs. It should be clear that no one component can neither effectively take the place of another, nor can data collected from one be used to arbitrarily substitute that which was not collected from another. Instead, each is used as a source of information on which to base decisions until such time as additional information has been collected from longer term research programs, to better understand data collected from other research studies, and to make informed decisions at various phases of pavement design initiatives. 


\section{History OF APT'S AND TheIr CONSTRUCTION DESIGNS}

APT's were first introduced to the world in 1912 when the United Kingdom created the "Road Machine". The idea soon infiltrated the United States in 1919 with the construction of the Arlington Test Road where concrete pavement designs were tested by loaded truck traffic. Over time, facilities like the Bates experimental road, Maryland Test Road, and the Western Association of State Highway Officials Road Test began to test pavements using simulated or actual traffic on test roads.

While the aforementioned experiments paved the way for future APT's, the frontrunner to modern APT facilities was the American Association of State Highway Officials (AASHO) Road test. This experiment began to elevate the rationality behind road construction and pavement design by developing empirical equations for design from the experiment's results.

While APT programs were developed globally over the next thirty years, APT usage came to the forefront of pavement design in the 1990s. In 1996, 28 APT experiments were located globally; however, by 2002, this number had grown to 45, 14 being inside the United States.

Over time various facilities were build varying in size, principle of how the artificial traffic load is applied and their construction designs. Fixed facilities (be it pulse, linear or circular) compose of loading device and replaceable pavement test section; mobile facilities are either heavy vehicle simulators which are basically mobile linear loading device that applie loads to small sample areas on full-scale pavements or towed linear test tracks that can also be used in the same way. There second main category of APT's facilities are test tracks which have either linear (uncommon) or roundoval shape and load is applied by either manned or unmanned test trucks.

TABLE II: DIFFERENCES RESULTING FROM CONSTRUCTION DESIGN OF APT'S

\begin{tabular}{|l|l|l|}
\hline Fixed facilities & Test tracks & Mobile facilities \\
\hline $\begin{array}{l}\text { Controlled temperature } \\
\text { and moisture }\end{array}$ & $\begin{array}{l}\text { Uncontrolled } \\
\text { temperature and } \\
\text { moisture }\end{array}$ & $\begin{array}{l}\text { Uncontrolled } \\
\text { temperature and } \\
\text { moisture }\end{array}$ \\
\hline Slow speed trafficking & $\begin{array}{l}\text { Highway speed } \\
\text { trafficking }\end{array}$ & $\begin{array}{l}\text { Slow speed } \\
\text { trafficking }\end{array}$ \\
\hline $\begin{array}{l}\text { Ability to vary load and } \\
\text { to overload }\end{array}$ & $\begin{array}{l}\text { Limited ability to } \\
\text { overload }\end{array}$ & $\begin{array}{l}\text { Ability to vary load } \\
\text { and to overload }\end{array}$ \\
\hline Short sections & Longer sections & Short sections \\
\hline Controlled wander & Uncontrolled wander & Controlled wander \\
\hline $\begin{array}{l}\text { Little or no suspension } \\
\text { interaction }\end{array}$ & $\begin{array}{l}\text { Realistic suspension } \\
\text { interaction }\end{array}$ & $\begin{array}{l}\text { Little or no } \\
\text { suspension interaction }\end{array}$ \\
\hline $\begin{array}{l}\text { Difficult to measure } \\
\text { roughness }\end{array}$ & $\begin{array}{l}\text { Meaningful roughness } \\
\text { measurement }\end{array}$ & $\begin{array}{l}\text { Difficult to measure } \\
\text { roughness }\end{array}$ \\
\hline
\end{tabular}

Apart from the apparent differences between fixed and mobile facilities/test tracks the subtle but from the viewpoint of pavement testing very important differences are listed in Table II

\section{APT Testing Methodology}

Depending on the type of ATP facility, the artificial load traffic can be applied anywhere between three months using load facilities to a few years in test tracks. Specific environmental conditions (e.g. temperature and moisture content) can be controlled for fixed facilities. Visual assessments and measurements are taken frequently, and are usually overseen by research staff involved in the particular study, while load repetitions, tire pressures and environmental conditions are accurately recorded on a continuous basis. Pavements are usually tested to failure and can be instrumented such that stresses, strains and permanent deformation in each layer and at the layer interfaces can be measured. Deflection and profile measurements are also taken. Test pits are usually excavated after trafficking to ensure a full understanding of the failure mechanism and the response of each pavement layer.

Comprehensive laboratory testing programs run in conjunction with the APT study to provide a broader spectrum of design parameters that can be assessed and related back to the APT trafficking. APT is considerably more expensive than laboratory testing and therefore only selected designs, derived from earlier laboratory-testing programs may be validated. As for the testing a minimal staff that is required for facility of University of ZA is listed below.

\section{Project Director}

Held accountable for:

- Developing a strategic APT program and experimental design

- Authorizing the establishment of new testing pavement section

- Motivating, justifying and ensuring sustainable funding

- Overall program management and accountability

- Quality management of outputs

- Strategic management and implementation of findings

- Industry liaison, coordination and feedback

Project Manager

Reports to the Project Director and held accountable for:

- Quality management of tested pavement section

- Project management and environmental, health and safety management

- Calibration and accreditation of instrumentation, procedures and facility itself

- Management of laboratory testing and control sample storage

- Appointment and management of other resources (instruments)

- Training and calibration of the Field Technician

- Liaison with the Database Manager to ensure that data is useable and in the correct format

- Analysis of results and reporting

- Management of maintenance interventions

Field Technician

Reports to the Project Manager and held accountable for:

- Safety in laboratory/testing site

- Loading device setting

- Instrumentation

- Routine monitoring and presentation of required results to the Database Manager

Database Manager

Reports to the Project Manager and held accountable for:

- On-time and accurate capture of data

- Database maintenance

- Facilitating report printing and distribution in suitable formats 
- Ensuring long-term availability and accessibility of all records in the database

\section{APt Testing Methodology}

The road network of Slovakia consists of $391 \mathrm{~km}$ of limited access roads (motorways and express roads) and $174367 \mathrm{~km}$ of $1^{\text {st }}, 2^{\text {nd }}$ and $3^{\text {rd }}$ class roads. Pavement management system of these roads was implemented in 1996. This system as well as the pavement design model is based on calculation of layered elastic half-space which is heavily reliant on correctness of data for used materials and design which can be confirmed or denied/changed. On top of that Slovakia is a suitable candidate for APT testing because is characterized by:

- Non-consolidated road network.

- Existing road network does not meet new requirements.

- Road sector and knowledge structures are not fully developed.

APT opens up various possibilities. The data gathered by this kind of testing proved very valuable and many significant findings were formulated in history of Civil Engineering by APT testing (Benefit of paved shoulders, development of Benkelman Beam, AC overlay design process, truck axle design, benefits of thick AC surfacing...).

The APT testing topics relevant for SR are:

- Evaluation of pavement materials.

- Development and calibration of design methods and performance models.

- Development and calibration of advanced models.

- Pavement maintenance and reinforcement.

- Effects of vehicle variables on pavement performance.

- Evaluation of new techniques for pavement condition survey.

- Evaluation of pavement environment related issues.

The crucial part is to design the APT facility to meet the requirements that arise from results we wish to achieve.

\section{A. Fixed Linear Accelerated Load Facility of University of Žilina}

The APT facility of University of Žilina will consist of a $2.5 \mathrm{~m}$ wide and $5.5 \mathrm{~m}$ long reaction frame with single or dual axle assemblies. The wheel axle assembly will be driven by electromotor which will enable a cycle of 10 mil. passes per 361 days e.g. frequency of $0.3206 \mathrm{~Hz}$.

Testing speed of the loading unit will be approximately 30 $\mathrm{km} / \mathrm{h}$ and will be able to deliver an artificial load up to $64 \mathrm{kN}$. The need for accurate instrumentation has always been a concern. Researchers need the ability to determine how the pavement is performing and why the pavement fails. A National Instruments PXI, cDAQ or equivalent equipment will be used as data acquisition system to collect data flow from 30 asphalt strain gages, 5 humidity and 8 temperature probes. The changing pavement characteristics will be measured with profilograph, deflectomer and other equipment needed.

Testing speed of the loading unit will be approximately 30 $\mathrm{km} / \mathrm{h}$ and will be able to deliver an artificial load up to $64 \mathrm{kN}$. The need for accurate instrumentation has always been a concern. Researchers need the ability to determine how the pavement is performing and why the pavement fails. A
National Instruments PXI, cDAQ or equivalent equipment will be used as data acquisition system to collect data flow from 30 asphalt strain gages, 5 humidity and 8 temperature probes. The changing pavement characteristics will be measured with profilograph, deflectomer and other equipment needed.

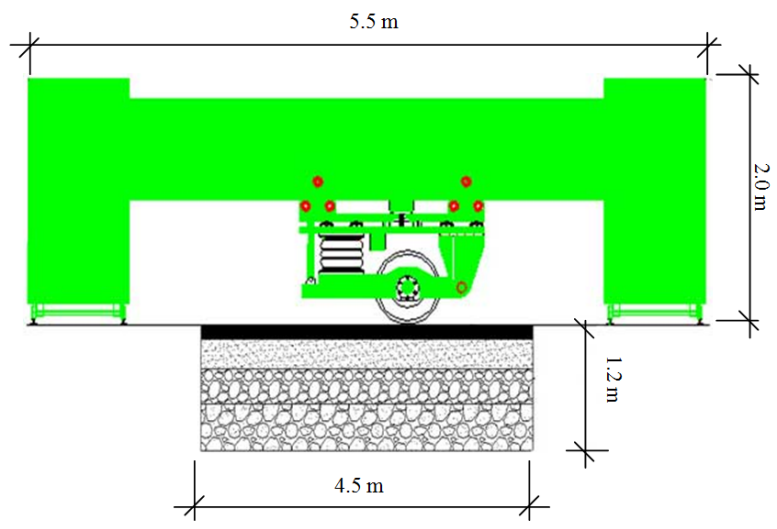

Fig. 2. APT facility of University of Žilina- draft

\section{B. Outputs and Usage of Gathered Data}

The raw outputs we aim to gather during APT tests are:

- Temperature at surface and in-depth.

- Surface deflections.

- Below-surface deflections.

- Below-surface strains.

- Below-surface permanent deformation.

- Water contents in unbound layers.

- Transverse surface profile.

- Crack mapping and Crack activity.

Other outputs that may be of value that can be gathered with the use of additional instruments:

- Noise measurements using on-board sound intensity.

- Surface texture and friction.

- Transverse surface profile (rutting-shoving).

- Observation of stripping.

The raw data gathered during testing will serve as a means of improving performance and economics of pavements. It should improve the understanding of the factors that affect pavement performance through the ability to

- Explore a wide variety of structural compositions and configurations.

- Simulate mechanisms, conditions, and processes through loading and environment.

- Test and characterization of materials.

- Analyze and understand response and performance.

The general philosophy of the research program will create the framework of APT program which development is the main responsibility of project director.

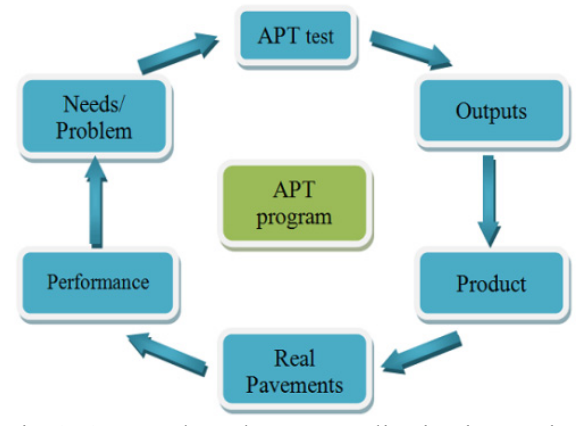

Fig. 3. APT cycle and output application in practice 
The APT program should have defined sequence of APT tests, definition of testing conditions and implementation of findings into real-life pavement management system. The APT program may be visualised as a cycle of testing, implementation of gathered data and finding of new issues which will need further testing and is shown in Fig. 3.

The acquired knowledge will be applied for enhancement and innovation in pavement engineering. Right interpretation of APT outputs will lead to:

- Unique, unconventional pavement structures evaluation.

- Evaluate failure mechanisms so that it will be possible to cost-effectively counteract distress mechanisms.

- Design evaluation and enhancement of a wide range of structural design packages.

- Systematic investigation of the vehicle-pavement-environment interaction.

- Pavement materials evaluation. (The answering of questions relating to the use of new materials, composite materials, and materials with complex physical characteristics.)

- Development and evaluation of performance models and validation of laboratory test procedures.

\section{REFERENCES}

[1] F. Hugo, Significant Findings from Full-Scale Accelerated Pavement Testing, National Cooperative Highway Research Program, ISBN 978-0309069748; Washington, D.C. 2004.
[2] M. L. Ralls, T. J. Kazmierowski, and B. Choubane, Use of Accelerated Pavement Testing to Evaluate Maintenance and Pavement Preservation Treatment, Transportation Research Board, Washington, D.C. 2009.

[3] A. Saeed, Accelerated Pavement Testing: Data Guides, National Cooperative Highway Research Program; Transport Research Board Trans. Image Process, ISBN 0-309-08783-X; Washington, D.C. 2003.

[4] D. Jones, P. P. Green, and E. Sadzik, "The development of a protocol for establishment and operation of LTPP sections in conjunction with APT section," CSIR Transportek 2011, South Africa, Pretoria 2011.

[5] J. R. Willis, "A synthesis of practical appropriate instrumentation use for accelerated pavement testing in the united states," in Proc. International Conference on Accelerated Pavement Testing, Spain, Madrid 2008

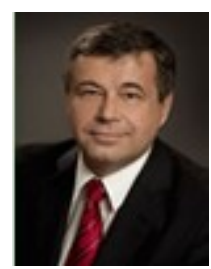

Ján Mikolaj is a leading expert on Pavemen Management Systems in Slovakia. After attaining the university professor degree on University of Zilina, Faculty of Civil Engineering professor Mikolaj officiated numerous posts related to civil engineering, politics and education. From 1995 till 1998 he attained the post of General Manager of the Slovak Road Administration. From 2002 till 2010 he performed as Deputy of the National Council of the Slovak Republic and from 2006 till 2010 he was entrusted as the Deputy Prime Minister and Minister of Education of the Slovak Republic. Currently, as university professor and Head of the Department of Construction Technology at University of Zilina. $\mathrm{He}$ is the leading research \& development expert on the project ITMS: 26220220112, Independent Research of Civil Engineering Construction for Increase in Construction Elements Effectiveness". Professor Mikolaj is a member of PIARC. He wrote a monography "Guide for New Methods of Financing and Public/Private Partnership" and numerous books and treatises mainly oriented at Pavement Management Systems and Pavement Performance Models. 